\title{
$\ll$ Research Note» \\ Identification of Two Types of Growth Hormone Receptor Mutations in Two Strains of Sex-linked Dwarf Chickens
}

\author{
Kenichi Tahara ${ }^{1}$, Akira Tsukada ${ }^{1}$, Takanobu Hanai ${ }^{1}$, Kenta Okumura ${ }^{1}$, Kikumi Yamada ${ }^{1}$, \\ Atsushi Murai ${ }^{1,2}$, Rikiya Yamamoto ${ }^{3}$, Makoto Maeno ${ }^{4}$, \\ Noboru Saito ${ }^{2,1}$ and Kiyoshi Shimada ${ }^{2}$ \\ ${ }^{1}$ Division of Applied Genetics and Physiology and \\ ${ }^{2}$ Avian Bioscience Research Center, Graduate School of Bioagricultural Sciences, Nagoya University, and \\ ${ }^{3}$ National livestock breeding center Okazaki station and \\ ${ }^{4}$ Hyogo Station
}

\begin{abstract}
Sex-linked dwarf (SLD) of White Leghorn (WL; S23MA line, Okazaki station, Japan) and White Plymouth Rock (WPR; 15 line, Hyogo station, Japan) strains were established from the MA line (WL) and 16 line (WPR) of a normal growing line, respectively. However, the responsible genes in the two lines of SLD chicken have not been identified. In this study, we characterized the phenotypes and identified the responsible genes in the SLD chickens of these two strains. SLD chickens of both strains showed low body weight, short tarsometatarsus length, and high blood growth hormone (GH) level compared with the normal growing lines. From these particular results, it was indicated that the SLD chickens might possess a defect in the growth hormone receptor (GHR). We identified two types of mutations in the GHR gene in each SLD chicken by Northern blot and polymerase chain reaction analyses. The S23MA line had a single base mutation in the splice donor site of the exon 5/intron 5 on the GHR gene, whereas the 15 line lacked a large part of exon 10 of the GHR gene, which contained 27 highly conserved amino acids at the $3^{\prime}$ end of the coding region and $3^{\prime}$-UTR. Furthermore, it was revealed that growth retardation was caused by reduction in food intake of the SLD chickens. These two genetically distinguishable lines of dwarf chickens would serve as an effective tool for analyzing novel GH function and GHR signal transduction in chickens.
\end{abstract}

Key words: genotyping, growth hormone, growth hormone receptor, growth hormone resistance, sex-linked dwarf chicken

J. Poult. Sci., 46: 249-256, 2009

\section{Introduction}

Sex-linked dwarf (SLD) chickens represents a genetic disorder characterized by low body weight and reduced levels of insulin-like growth factor (IGF)-I despite high concentrations of growth hormone $(\mathrm{GH})$ in plasma (Hoshino et al., 1982; Tixier-Boichard et al., 1989; Decuypere et al., 1991; Buyse et al., 1994). This genetic disorder is due to mutation on the $\mathrm{Z}$ chromosome of a recessive growth hormone receptor (GHR) gene (Guillaume, 1976; Burnside et al., 1991; Huang et al., 1993; Agarwal et al., 1994; Hull et al., 1995; Tanaka et al., 1995, 1996). The SLD chicken is suggested to be the animal model for GH resistance, as well as the first model of Laron syndrome in humans (Laron, 1993).

SLD chickens are highly heterogeneous, and several

Received: November 17, 2008, Accepted: February 4, 2009

Correspondence: Dr. A. Tsukada, Division of Applied Genetics and Physiology, Graduate School of Bioagricultural Sciences, Nagoya University, Nagoya, Japan.

(E-mail: tsuka@nuagr1.agr.nagoya-u.ac.jp) different mutations have been identified in the GHR gene; for example, in Georgia SLD and Gifu 20 SLD, a single base mutation of the splice donor site in exon 5/intron 5 has been identified to result in exclusive expression of a small GHR transcript (Huang et al., 1993; Tanaka et al., 1995), and in Cornell SLD and Leghorn SLD, a point mutation has been identified to result in a serine-isoleucine substitution in the extracellular domain, which impairs the binding activity of GH with the mutant GHR (Duriez et al., 1993; Hull et al., 1995). In another type of SLD strain, the so-called Connecticut SLD, a deletion has been identified in the GHR gene, which causes the removal of 27 amino acids from the carboxyl terminal of GHR (Burnside et al., 1991; Agarwal et al., 1994). All these mutations result in a GHR defect or a dysfunctional GHR protein.

The White Leghorn (WL; S23MA line, National Livestock Breeding Center, Okazaki station, Japan) and White Plymouth Rock (WPR; 15 line, National Livestock Breeding Center, Hyogo station, Japan) strains maintained in Japan were established from the MA line (WL) and 16 
line (WPR) of a normal growing line, respectively. However, the responsible genes in the two strains of SLD chicken have not been identified. In this study, we characterized the phenotypes and identified the responsible genes in two strains [meat-type (WPR) and egg-type strains (WL)] of SLD.

\section{Materials and Methods}

\section{Experimental Animals}

We used the MA line (normal chicken) and the S23MA line (dwarf chicken) of WL, which are maintained at the National Livestock Breeding Center, Okazaki station, and the 16 line (normal chicken) and 15 line (dwarf chicken) of WPR, which are maintained at the National Livestock Breeding Center, Hyogo station in Japan. The fertile eggs were incubated at $39^{\circ} \mathrm{C}$ under $85 \%$ relative humidity in an incubator apparatus for hatching (Showa Furanki, Urawa, Japan). The chicks were maintained in a heated battery brooder (Zenkei Battery Brooder, The ZENKEIEN CO., Ltd. Hamamatsu, Japan) until the age of 4 weeks, and then transferred to wire cages where they were fed a commercial diet and water. Body weight, tarsometatarsus length, and food intake were measured daily in individual cages. The handling of the birds was in compliance with the Guidelines of the Nagoya University Policy on Animal Care and Use. Blood samples were collected from the median wing vein of the adult chickens, and then separated into plasma and blood cells. The genomic DNA were extracted from blood cells according to a previously described standard method with modification (Sakimura et al., 2002) and the genomic DNA was stored at $4{ }^{\circ} \mathrm{C}$ until use. Plasma samples were stored at $-80^{\circ} \mathrm{C}$ until use. Liver samples were quickly excised, frozen in liquid nitrogen, and stored at $-80^{\circ} \mathrm{C}$ until use. All samples were obtained from 30 week-old male chickens.

\section{Radioimmunoassay}

Plasma GH concentration was measured in adult male WL and WPR normal and dwarf chickens using a doubleantibody radioimmunoassay (RIA) according to a previously described method with modification (Tsukada et al., 1998). We used purified chicken GH for iodination and standard, and an anti-chicken GH antibody raised in rabbits (provided by Dr. A. F. Parlow, Pituitary Hormones and Antisera Center, National Hormone and Peptide Program, Harbor-University of California Los Angeles Medical Center, Torrance, CA, USA). A parallelism study was performed to validate the RIA results.

\section{Northern Blot Analysis of Chicken GHR mRNA}

Total RNA was extracted from the liver using the acid guanidinium-phenol-chloroform method (Chomczynski and Sacchi, 1987). Hepatic RNA samples $(20 \mu \mathrm{g})$ were separated on $1 \%(\mathrm{w} / \mathrm{v})$ agarose gel containing $2.2 \mathrm{M}$ formaldehyde. The separated RNA was blotted onto a nylon membrane (Hybond + , GE Healthcare, BKM, UK) and hybridized with a radiolabeled chicken GHR cDNA probe reported previously (Tsukada et al., 1998). The amount of mRNA was quantitatively determined by a Fuji
BAS 2000 Bioimaging Analyzer (Fujifilm, Tokyo, Japan). Genotyping of Splice Donor Site Single Base Mutation in GHR Exon 5/intron 5

To identify the splice donor site single base mutation in exon 5 /intron 5 on the GHR gene, two different sense primers (GT-type; 5'-TCAGTGTTGATGAAATAGGT$3^{\prime}$ and GC-type; 5'-TCAGTGTTGATGAAATAGGC-3') and a common antisense primer ( $5^{\prime}$-TGGATCCCAGTTTGACTAGT- $\left.3^{\prime}\right)$ were used for the normal and dwarf chickens (summarized in Fig. 4). PCR was performed in a $10-\mu 1$ mixture containing $50 \mathrm{ng}$ of genomic DNA, $0.4 \mu \mathrm{M}$ of each primer, $0.1 \mathrm{U}$ of AmpliTaq Gold DNA polymerase (Applied Biosystems, Foster City, CA, USA), $0.8 \mathrm{mM}$ deoxynucleoside triphosphate mixture, and one-tenth $10 \times$ PCR buffer. Genomic DNA (50 ng) samples, extracted from the normal and dwarf WL chickens, were amplified with initial denaturation at $95^{\circ} \mathrm{C}$ for $1 \mathrm{~min}$, followed by 34 cycles of $95^{\circ} \mathrm{C}$ for $20 \mathrm{~s}, 59^{\circ} \mathrm{C}$ for $10 \mathrm{~s}$, and $72^{\circ} \mathrm{C}$ for $1 \mathrm{~min}$, with a final extension at $72^{\circ} \mathrm{C}$ for $1 \mathrm{~min}$. The PCR products were separated on a $0.8 \%$ agarose gel and stained by ethidium bromide.

Genotyping of a Large Deletion on the GHR Exon 10 in WPR Dwarf and Sequencing of Truncated GHR Gene

We used the primer pair (sense primer; 5'-ATTGTTCACTCTCCACAAGGC-3', antisense primer; 5'-GATTCTCCTGGCAGAATCTC-3') for identification of a large deletion on the GHR exon 10 in the WPR dwarf (summarized in Fig. 4) as reported previously (Agarwal et al., 1994). PCR was performed in a $10-\mu l$ mixture containing $50 \mathrm{ng}$ of genomic DNA, $0.4 \mu \mathrm{M}$ of each primer, $0.1 \mathrm{U}$ of HybriPol DNA Polymerase (BIOLINE, UK), $0.8 \mathrm{mM}$ deoxynucleoside triphosphate mixture, and one-tenth $10 \times$ PCR buffer. Genomic DNA (50 ng) samples, extracted from WPR normal and dwarf chickens, were amplified with initial denaturation at $96^{\circ} \mathrm{C}$ for $1 \mathrm{~min}$, followed by 32 cycles of $96^{\circ} \mathrm{C}$ for $20 \mathrm{~s}, 57^{\circ} \mathrm{C}$ for $10 \mathrm{~s}$, and $72^{\circ} \mathrm{C}$ for $45 \mathrm{~s}$, with a final extension at $72^{\circ} \mathrm{C}$ for $1 \mathrm{~min}$. The PCR products were separated on a $0.8 \%$ agarose gel and stained by ethidium bromide. Then, the amplified GHR fragment from the WPR dwarf samples was cloned into the pGEM-T easy vector (Promega, Madison, WI, USA) and sequenced (Sanger et al., 1997).

\section{Results}

\section{Characterization of the Two Sex-linked Dwarf Chickens}

Photographs of the two strains and two lines of chickens are shown in Figure 1A. Body weight increased during the growth stage in both strains. Understandably, the body weight of the meat-type strain (WPR) was higher than the egg-type strain (WL); however, the body weight of the $\mathrm{S}$ 23MA and 15 line (dwarf) chickens was about 40\% lower at the age of 12 weeks compared with the normal growing chickens (MA line and 16 line) (Fig. 1B, C). Dwarf chickens of both the strains had about 20\% shorter tarsometatarsus length than normal growing chicken at the age of 12 weeks (Fig. 1D, E). Among male WL chickens, plasma $\mathrm{GH}$ concentrations of the S23MA line 
White Leghorn

(WL)

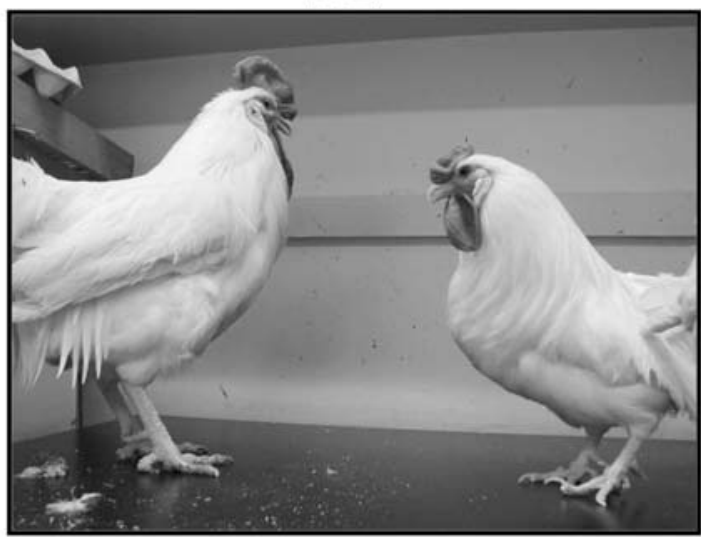

MA line

(Normal)

B

WL

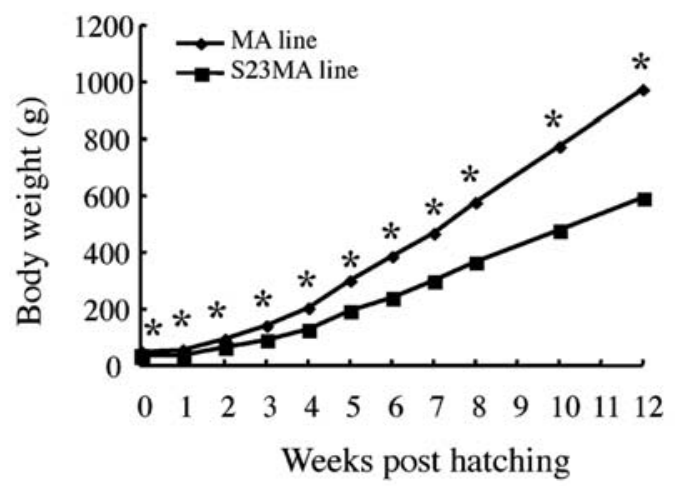

C

WPR

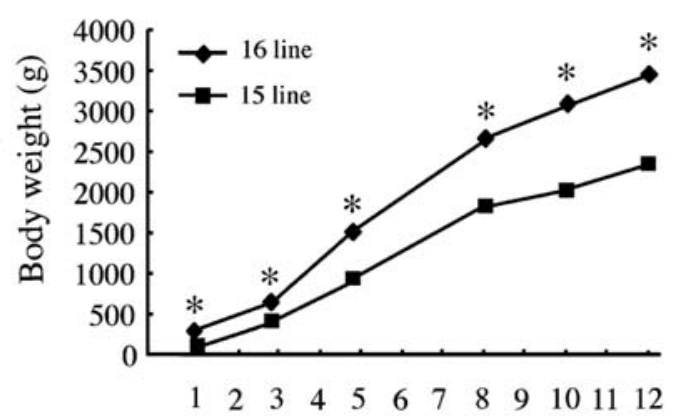

Weeks post hatching
A

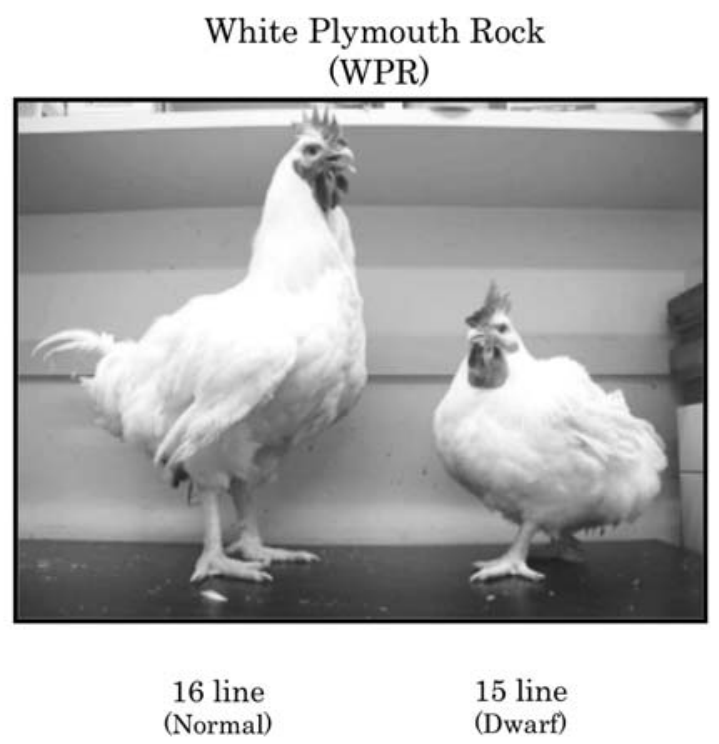

D

WL

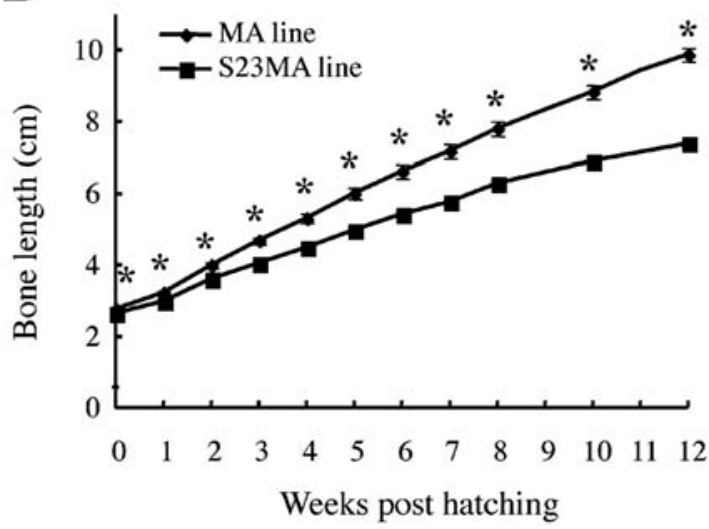

E

WPR

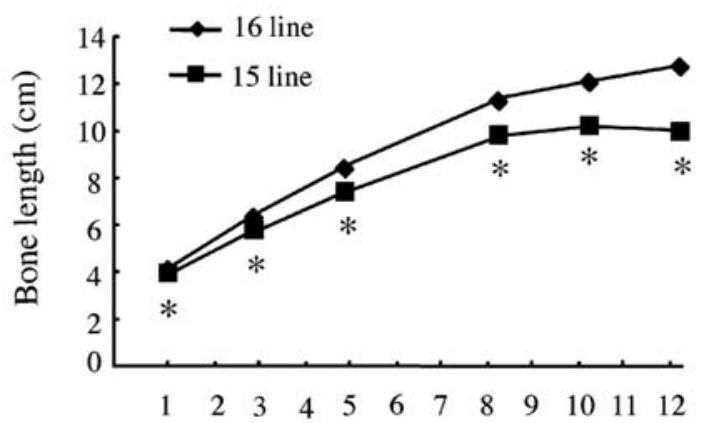

Weeks post hatching

Fig. 1. Somatic growth in dwarf and normal WL and WPR male chickens. (A) Photographs of adult male MA line (normal) and S23MA line (dwarf) of the WL strain (left panel), and those of the adult male 16 line (normal) and 15 line (dwarf) of the WPR strain (right panel). (B and C) Body weight of normal and dwarf male chickens of the WL and WPR strains $(\mathrm{N}=5-30)$ in the primary growth stage. (D and E) Tarsometatarsus length of normal and dwarf male chickens of the WL and WPR strains $(\mathrm{N}=5-30)$ in the primary growth stage. The values are mean \pm SEM. $* P<0.05$ (normal vs. dwarf). 
Table 1. Comparison of feed conversion between normal and dwarf lines of chicken belonging to White Leghorn and White Plymouth Rock strains

\begin{tabular}{cccccc}
\hline \hline Strain & Line & BWG $(\mathrm{g})$ & Food intake $(\mathrm{g})$ & Feed conversion & $\mathrm{n}$ \\
\hline \multirow{2}{*}{ WL } & MA & $38.0 \pm 5.8$ & $110.9 \pm 10.9$ & $0.34 \pm 0.03$ & 4 \\
& S23MA & $20.5 \pm 2.8^{*}$ & $65.3 \pm 9.3^{*}$ & $0.32 \pm 0.02$ & 6 \\
\hline \multirow{2}{*}{ WPR } & 16 & $193.0 \pm 4.9$ & $276.6 \pm 16.5$ & $0.71 \pm 0.03$ & 5 \\
& 15 & $97.3 \pm 12.7^{* * *}$ & $154.1 \pm 11.3^{* * *}$ & $0.64 \pm 0.07$ & 6 \\
\hline
\end{tabular}

Abbreviation: WL, white leghorn; WPR, white plymouse rock; BWG, body weight gain. Results are reported as means \pm SEM during 1-2 week after post hatched.

$*=P<0.05$ and $* * *=P<0.001$.

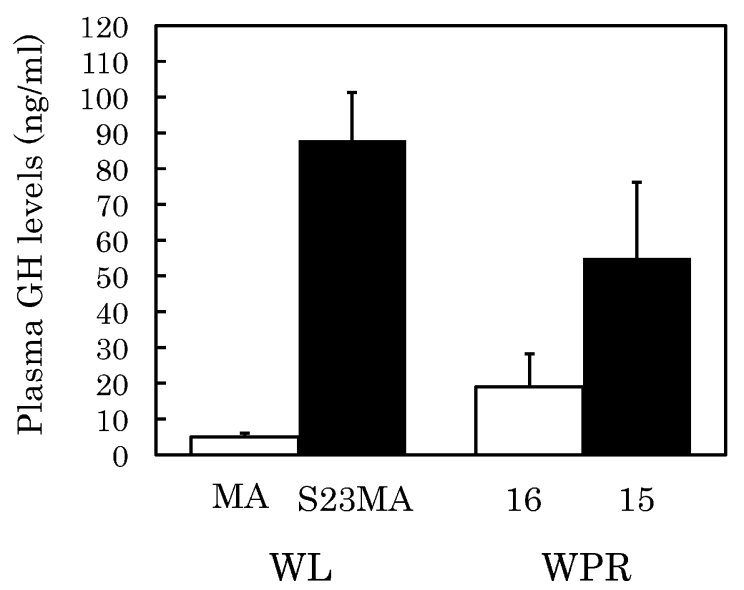

Fig. 2. Serum GH concentrations of normal and dwarf male chickens belonging to the WL and WPR strains. Blood was collected from 4-5 adult chickens, and serum $\mathrm{GH}$ concentrations were measured. The values are mean \pm SEM.

chickens were significantly higher, about 18-fold, than that of the MA line chickens (Fig. 2). Correspondingly, among the WPR strain chickens, plasma GH concentration of the 15 line chickens was about 3-fold higher than that of the 16 line chickens.

The body weight gain and food intake of the S23MA line and 15 line were significantly less than the MA line and 16 line, respectively. In contrast, there were no significant differences in the feed conversions between the normal and dwarf lines of both strains (Table 1).

The Two Strains of Dwarf Chicken were Genetically Distinguishable by a Difference in the GHR Gene Mutation

The Northern blot analysis identified abnormally sized GHR transcripts in dwarf chickens of both strains (Fig. 3 ). In the normal growing chickens of the WL and WPR strains, a major transcript of approximately $4.5 \mathrm{~kb}$ was detected with a less abundant smaller transcript $(3.7 \mathrm{~kb})$. In the S23MA line of the WL strain, an approximately 0.8 $\mathrm{kb}$ abnormal transcript was detected as the major transcript. In addition, GHR variants of $5.5 \mathrm{~kb}$ and $4.7 \mathrm{~kb}$, instead of the $4.5 \mathrm{~kb}$ and $3.7 \mathrm{~kb}$ transcripts, were observed in the S23MA line. In contrast, the 15 line chicken of the

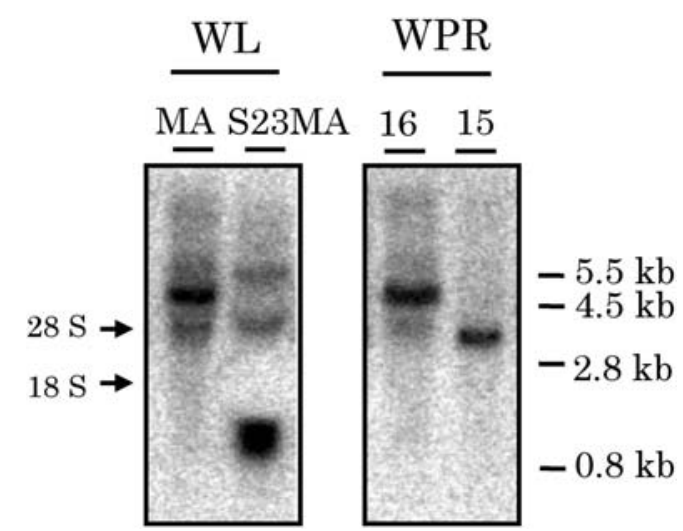

Fig. 3. Variants of hepatic GHR mRNA detected by Northern blot analysis in normal (MA and 16 lines) and dwarf chickens (S23MA and 15 lines). 28S and 18S ribosomal RNA are indicated by arrows. Size of the various GHR mRNAs is indicated in the right margin.

WPR strain had a single 2.8-kb hepatic GHR transcript. These variant mRNAs have been reported previously (Agarwal et al., 1994), but were not found in the normal growing chicken.

Subsequently, we performed genotyping PCR analysis to identify these heterogenic GHR in the two dwarf lines. DNA samples of the MA line were amplified by a GT-type primer, but not by a GC-type primer. DNA samples of the S23MA line were amplified by a GC-type primer, but not by a GT-type primer (Fig. 4A). However, the primer pair to determine the deletion at the GHR-exon 10 could be amplified to flank a 2-kbp region of the normal WPR 16 line GHR gene. An approximately 250-bp product was amplified as a truncate form using genomic DNA of the 15 line dwarf chicken (Fig. 4B). The truncated cDNA of the 15 line was $1.7-\mathrm{kbp}$ smaller than that of the 16 line having the wild-type GHR gene. After cloning and sequencing the truncated cDNA from amplified 15 line samples, it was revealed that this region of the GHR lacked 81 nucleotides of coding region (coding for 27 amino acids at the C-terminus) and $1692 \mathrm{bp}$ of the $3^{\prime}$ UTR of the wildtype GHR gene (Fig. 5A). The deleted region included the translational stop codon. The predicted amino acid sequences of the C-termini of the wild-type GHR and 


\section{(A)}

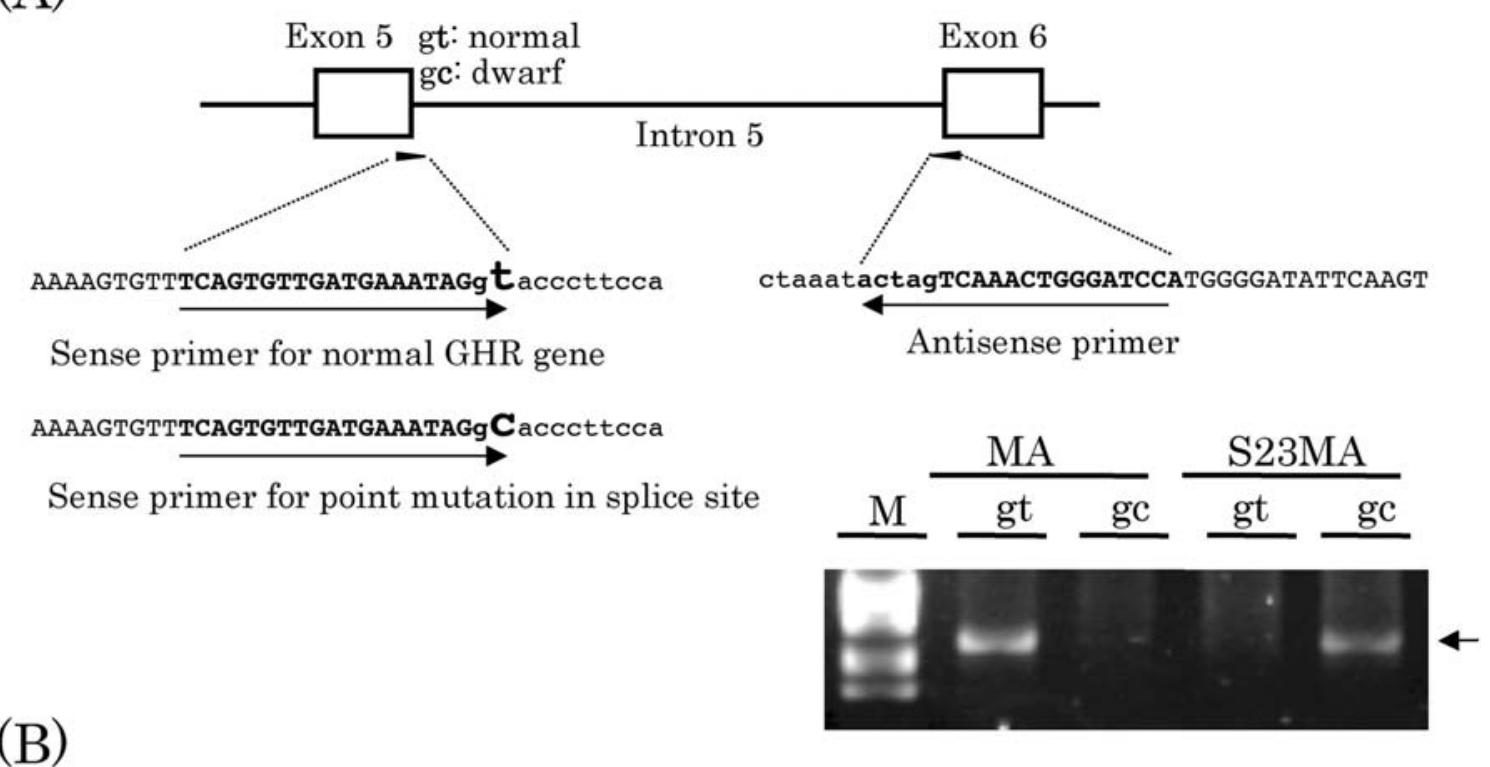

(B)

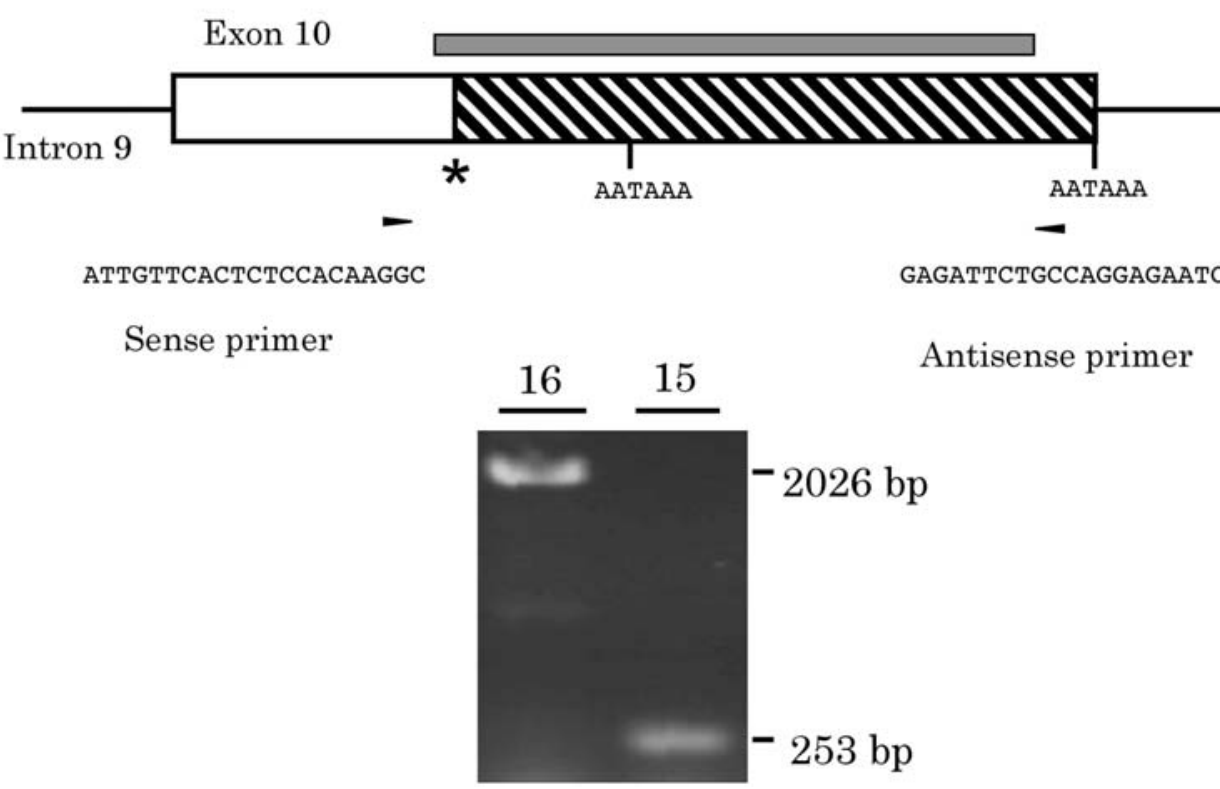

Fig. 4. Genotyping of GHR with the putative mutation region. (A) Schematic representation of the genotyping of $\mathrm{T}$ to $\mathrm{C}$ conversion in the exon 5/intron 5 junction using PCR primers. The electrophoresis reveals the PCR analysis of the MA and S23MA lines with these primers. (B) Schematic representation of the genotyping of the putative mutation, which is a large deletion in exon 10, using PCR primers. The electrophoresis shows the genotyping of the 15 and 16 lines using these primers. Deleted region in the gene is shown by a thin gray box. ORF of exon 10 is boxed, and the $3^{\prime}$-UTR is indicated by a shaded box. The position of the stop codon is indicated by an asterisk.

abnormal truncated form is shown in Fig. 5B.

\section{Discussion}

Previous studies have reported that dwarf chickens eat less, gain less body weight, and have higher blood GH levels than normal chickens (Hoshino and Yamamoto,
1977; Marks 1980, 1983; Scanes et al., 1983; Stewart et al., 1984). However, these studies did not consider SLD chickens and their etiological genetic backgrounds. Burnside et al. reported that GHR transcript in SLD chicken was shorter than that in normal growing chicken having wildtype GHR (1991). Other SLD chickens of GHR deficie- 


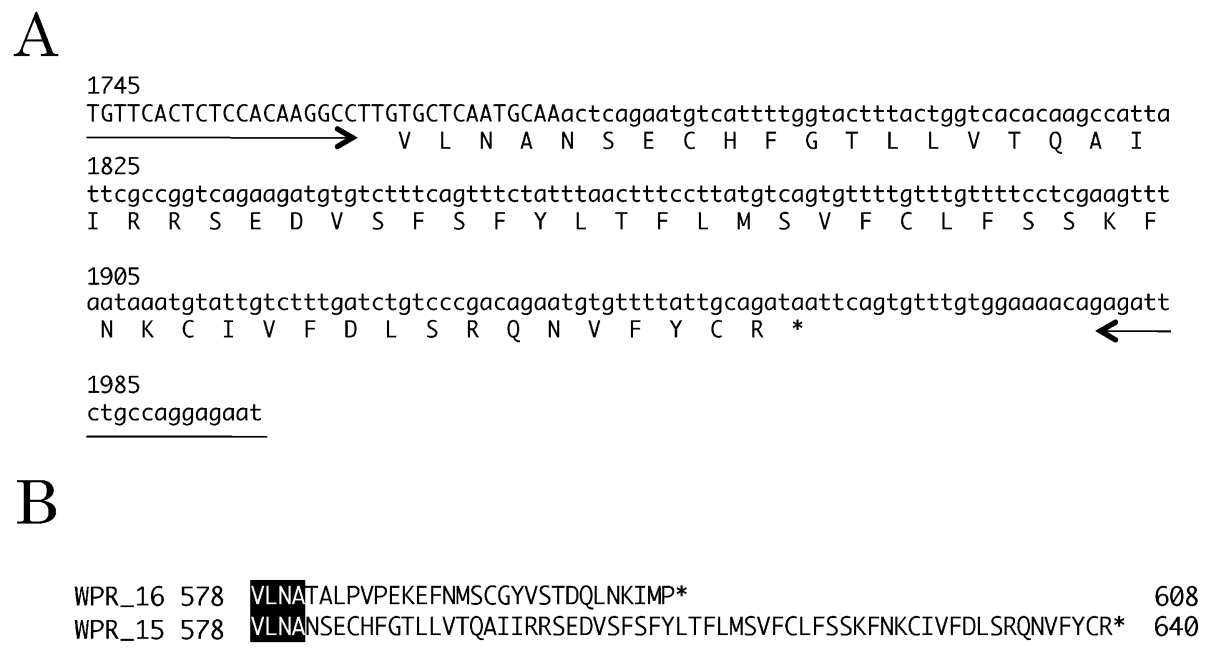

Fig. 5. Nucleotide and predicted amino acid sequence of the partial GHR gene in the 15 and 16 lines with the deleted region. (A) The nucleotide and deduced amino acid sequences are shown from nucleotide 1745 (GI; 211810). Upper scale (nt) corresponds to normal-growing line (16 line) and the lower scale (nt) indicates the substituted sequence in the dwarf line (15 line). Arrows indicate the primer used. (B) The deduced amino acid sequence of the carboxyl-terminal regions of GHR from 16 line and 15 line. Corresponding sequences are indicated within the black box.

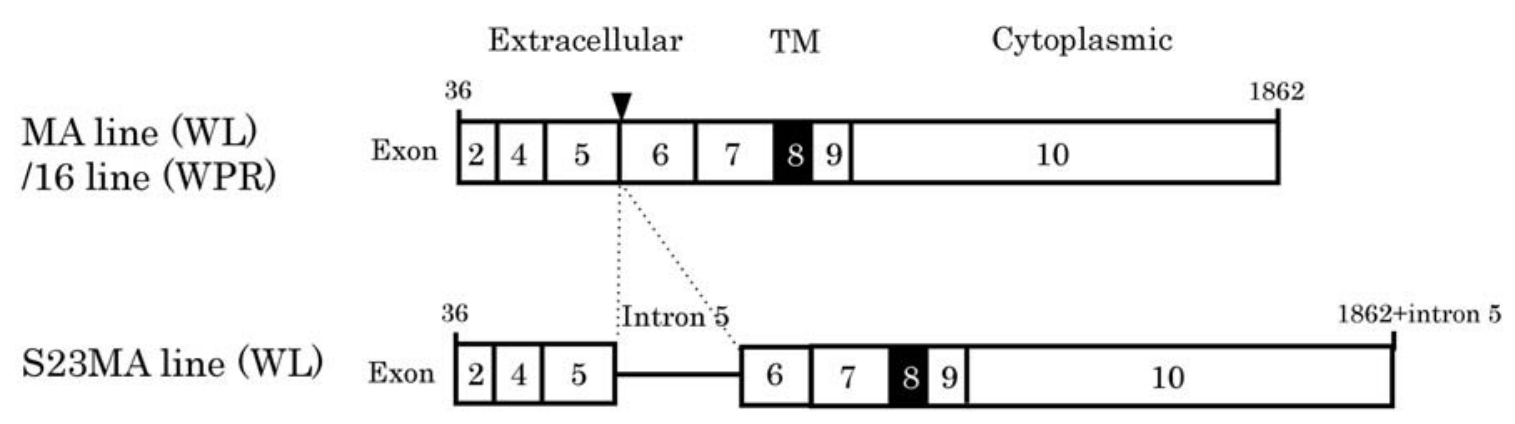

Intron5 inserted

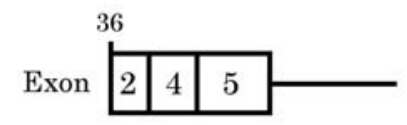

15 line (WPR)

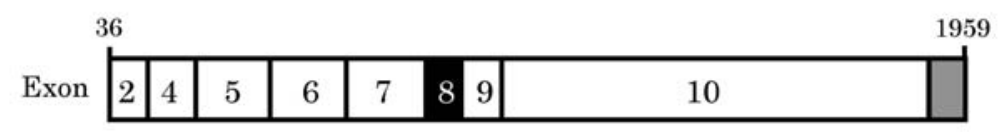

Deleted proper carboxyl-terminal 27 residues

Fig. 6. Schematic representation of the deduced normal and dwarf (WL and WPR) strains of the GHR mRNA structure. Location of exons is shown, but the presence of a chicken homolog for exon 3 has not been determined. Numbers indicate nucleotides from the transcription start site. The transmembrane domain (TM) is indicated by a black box. The position of intron 5 is indicated by an arrowhead. Substituted sequence in the 15 line of the WPR strain is indicated by a gray box. 
ncy were have been reported (Huang et al., 1993; Agarwal et al., 1994; Hull et al., 1995; Tanaka et al., 1995, 1996). High GH levels have been reported in GHR-deficient dwarf humans (Laron et al., 1966a, b) and mice (Rowland et al., 2005). Moreover, high GH levels have been reported in GHR-deficient dwarf chickens (Vasilatos-Younken et al., 1997). Our results of low body weight, shorter tarsometatarsus length (Fig. 1), half the amount of feed intake (Table 1), and high plasma GH concentration (Fig. 2) suggested that the S23MA and 15 line chickens are typical GH-defective dwarf chicken lines.

The Northern blot analysis indicated that the two dwarf lines have different types of mutated GHRs. The 5.5- and 0.8-kb aberrant GHR mRNAs in the S23MA line corresponded to those reported for the Gifu20 and Georgia SLD (GA line), which occurs due to a mutation of the splice donor site in the exon 5/intron 5 (Huang et al., 1993; Tanaka et al., 1995). In contrast to this, the $2.8-\mathrm{kb}$ aberrant GHR mRNA in the 15 line corresponded to the Connecticut SLD (CT line), which occurs as a result of a large deletion in exon 10 of the GHR gene (Agarwal et al., 1994). Furthermore, both genotyping PCR methods identified the mutations in the GHR gene. Thus, we determined two types of mutations in the egg-type and meat-type SLD chickens. The S23MA layer line has a single base mutation of the splice donor site in the exon 5/ intron 5 on the GHR gene, whereas the 15 line lacked the large part of exon 10, which contained the $3^{\prime}$ end of the coding region with 27 highly conserved amino acids and the $3^{\prime}$-UTR (Fig. 6). Agarwal et al. (1994) showed that the truncated GHR in the CT line is translated as a reasonably sized GHR protein. They deduced amino acids sequence of the C-terminal GHR protein that the truncated GHR mRNA which have poly A signal and no stop codon translated reasonable size of GHR which have poly lysine C-terminus. However, we found the novel stop codon downstream of the deleted region and therefore considered that the deduced mutated GHR sequence of amino acids might be leading to the putative additional translational stop codon at 1956-1958 nt (Fig. 5A). Consequently, the last 27 amino acids of the GHR in the 16 line, as in the wild-type GHR, might be a substituted heteromorphic 32 amino acids, as in the mutated GHR protein (Fig. 5B).

We could compare the two different types of mutations; a single base transversion (S23MA line) and deletion of exon 10 on GHR (15 line) between the egg-type (WL) and meat-type (WPR) chicken strains. Understandably, the tarsometatarsas length, body weight, body weight gain, food intake, and feed conversion of the WL and WPR strains were significantly different; however, in the dwarfs of these strains, these were 20\%, 40\%, 50\%, and $40 \%$ less than those of the normal growing chickens, respectively, despite belonging to different strains. Thus, these parameters might have resulted from a GHR defect or possibly a different type of mutation. Additionally, feed conversion of the S23MA and 15 lines (94\% and 90\%, respec- tively) were similar to that of the normal growing chickens, which might also be caused by a GHR defect. The reduced body weight in the two dwarf lines was caused by food intake. In other words, food consumption might be controlled by GH. Plasma GH levels of the S23MA line were significantly higher, about 18 -fold, than that of the MA line in the WL strain (Fig. 2). Correspondingly, the concentration of plasma $\mathrm{GH}$ of the 15 line was about 3 -fold higher than that of the 16 line in the WPR strain. A similar result has been previously reported in female WPR chickens, which have a type of single base mutation in the splice donor site on exon 5/intron 5 of the GHR, resulting in 18-fold higher $\mathrm{GH}$ levels than normal growing chickens (Vasilatos-Younken et al., 1997). Thus, very high GH levels were observed in WL and WPR. Therefore, the single base mutation might be responsible for this large difference in GH levels, but not in the strain. The reason for the difference between the $\mathrm{GH}$ levels of each dwarf strain remains unclear. It could be associated with the breed (egg-type vs. meet-type) or it might be due to a difference in the type of GHR mutation. However, because there are few reports about C-terminal mutations, such as the 15 line-type GHR mutation, further investigation using dwarf chickens of this line might be necessary. Moreover, the same genetic background within these two distinguishable mutated GHRs allows for a detailed investigation of chicken GHR physiological functions and molecular mechanisms.

The SLD chickens might represent a good model for Laron syndrome, and provide important insight into structure-function relationships of GHR, GH physiology, and economical traits. In addition, $\mathrm{GH}$ plays a major role in cell proliferation, development, fatty acid metabolism, carbohydrate metabolism, protein synthesis, reproduction, extended life span, and normal growth. However, little is known about the mechanisms of action of $\mathrm{GH}$ in various tissues, except in the pituitary and liver. SLD chickens are good experimental and economical models for studying various GH functions. Moreover, the 15 line of the WPR strain would be useful for the analysis of GHR signaling domains and pathways.

\section{Acknowledgments}

We thank Nagoya University Radioisotope Center for all the facilities, and Dr. A. F. Parlow for providing the chicken GH RIA system. This work was supported in part by Grant-in-Aid for Young Scientists (B) (No. 18780211 to A. T.) from the Ministry of Education, Culture, Sports, Science and Technology, Japan.

\section{References}

Agarwal SK, Cogburn LA and Burnside J. Dysfunctional growth hormone receptor in a strain of sex-linked dwarf chicken: evidence for a mutation in the intracellular domain. Journal of Endocrinology, 142: 427-434. 1994.

Burnside J, Liou SS and Cogburn LA. Molecular cloning of the chicken growth hormone receptor complementary deoxyri- 
bonucleic acid: mutation of the gene in sex-linked dwarf chickens. Endocrinology, 128: 3183-3192. 1991.

Buyse J, Tixier-Boichard M, Berghman LR, Huybrechts LM and Decuypere E. Growth hormone secretory characteristics of sex-linked dwarf and normal-sized chickens reared on a control or on a 3,3',5-triiodothyronine-supplemented diet. General and Comparative Endocrinology, 93: 406-410. 1994.

Chomczynski $\mathrm{P}$ and Sacchi N. Single-step method of RNA isolation by acid guanidinium thiocyanate-phenol-chloroform extraction. Anal Biochem., 162: 156-159. 1987.

Decuypere E, Huybrechts LM, Kuhn E, Tixier-Boichard M and Merat P. Physiological alterations associated with the chicken sex-linked dwarfing gene. Critical Reviews in Poultry Biology, 3: 191-221. 1991.

Duriez B, Sobrier ML, Duquesnoy P, Tixier-Boichard M, Decuypere E, Coquerelle G, Zeman M, Goossens $\mathbf{M}$ and Amselem S. A naturally occurring growth hormone receptor mutation: in vivo and in vitro evidence for the functional importance of the WS motif common to all members of the cytokine receptor superfamily. Molecular Endocrinology, 7: 806-814. 1993.

Guillaume J. The dwarfing gene $d w$ : Its effects on anatomy, physiology, nutrition, management. World's Poultry Science Journal, 32: 285-304. 1976.

Hoshino S and Yamamoto K. Synthesis and release of growth hormone, prolactin, and other proteins from the anterior pituitary of normal and dwarf chickens. General and Comparative Endocrinology, 32: 7-16. 1977.

Hoshino S, Wakita M, Suzuki M and Yamamoto K. Changes in a somatomedin-like factor and immunoassayable growth hormone during growth of normal and dwarf pullets and cockerels. Poultry Science, 61: 777-784. 1982.

Huang N, Cogburn LA, Agarwal SK, Marks HL and Burnside J. Overexpression of a truncated growth hormone receptor in the sex-linked dwarf chicken: evidence for a splice mutation. Molecular Endocrinology, 7: 1391-1398. 1993.

Hull KL, Janssens WC and Harvey S. A missense mutation in the Cornell sex-linked dwarf (SLD) growth hormone receptor gene does not prevent plasma GH-binding. Poultry and Avian Biology Review, 6. 9.11 (Abstract). 1995.

Laron Z, Pertzelan A and Mannheimer S. Genetic pituitary dwarfism with high serum concentation of growth hormonea new inborn error of metabolism? Israel Journal of Medical Sciences, 2: 152-155. 1966a.

Laron Z, Mannheimer S, Pertzelan A and Nitzan M. Serum growth hormone concentration in full term infants. Israel Journal of Medical Sciences, 2: 770-773. 1966b.

Laron Z. An update on Laron syndrome. Archives of disease in childhood, 68: 345-346. 1993.

Marks HL. Growth, feed intake, and feed conversion of dwarf and nondwarf broiler-type chickens. Poultry Science, 10: 2183-2188. 1980.

Marks HL. Selection for body weight at eight weeks old in dwarf and normal meat-type chickens originating from a common control population background. Poultry Science, 62: 227234. 1983.

Rowland JE, Lichanska AM, Kerr LM, White M, d'Aniello EM, Maher SL, Brown R, Teasdale RD, Noakes PG and Waters MJ. In vivo analysis of growth hormone receptor signaling domains and their associated transcripts. Molecular and Cellular Biology, 25: 66-77. 2005.

Sakimura M, Tsukada A, Usami M, Hanzawa S, Saito N, Ohno $\mathrm{Y}$ and Shimada K. Effect of estradiol and nonylphenol on mRNA expression of estrogen receptors $\alpha$ and $\beta$, and cytochrome P450 aromatase in the gonad of chicken embryos. Journal of Poultry Science, 39: 302-309. 2002.

Sanger F, Nicklen S and Coulson AR. DNA sequencing with chain-terminating inhibitors. Proceedings of the National Academy of Sciences of the United States of America, 74: 5463-5467. 1977.

Scanes CG, Marsh J, Decuypere E and Rudas P. Abnormalities in the plasma concentrations of thyroxine, tri-iodothyronine and growth hormone in sex-linked dwarf and autosomal dwarf White Leghorn domestic fowl (Gallus domesticus). Journal of Endocrinology, 97: 127-135. 1983.

Stewart PA, Washburn KW and Marks HL. Effect of the dw gene on growth, plasma hormone concentrations and hepatic enzyme activity in a randombred population of chickens. Growth, 48: 59-73. 1984.

Tanaka M, Hayashida Y, Wakita M, Hoshino S and Nakashima K. Expression of aberrantly spliced growth hormone receptor mRNA in the sex-linked dwarf chicken, Gifu 20. Growth Regulation, 5: 218-223. 1995.

Tanaka M, Hayashida Y, Sakaguchi K, Ohkubo T, Wakita M, Hoshino S and Nakashima K. Growth hormone-independent expression of insulin-like growth factor I messenger ribonucleic acid in extrahepatic tissues of the chicken. Endocrinology, 137: 30-34. 1996.

Tixier-Boichard M, Huybrechts LM, Kuhn E, Decuypere E, Charrier $\mathbf{J}$ and Mongin P. Physiological studies on the sex-linked dwarfism of the fowl: A review on the search for the gene's primary effect. Genetics Selection Evolution, 21: 217-234. 1989.

Tsukada A, Ohkubo T, Sakaguchi K, Tanaka M, Nakashima K, Hayashida Y, Wakita M and Hoshino S. Thyroid hormones are involved in insulin-like growth factor-I (IGF-I) production by stimulating hepatic growth hormone receptor (GHR) gene expression in the chicken. Growth Hormone \& IGF Research, 8: 235-242. 1998.

Vasilatos-Younken R, Dunnington EA, Siegel PB and McMurtry JP. Tissue-specific alterations in insulin-like growth factor-I concentrations in response to 3,3',5-triiodo-L-thyronine supplementation in the growth hormone receptor-deficient sexlinked dwarf chicken. General and Comparative Endocrinology, 105: 31-39. 1997. 